\title{
The Effecting of Physical Properties of Inorganic Fillers on Swelling Rate of Rubber Compound: A review Study
}

\author{
${ }^{1}$ Salih Abbas Habeeb $\quad{ }^{2}$ Zoalfokkar Kareem Alobad \\ ${ }^{1,2}$ Polymers and Petrochemical Industries Department, Faculty of Materials Engineering, \\ University of Babylon, Al-Hilla city, Iraq \\ ${ }^{3}$ Muayad Abdulhasan Albozahid \\ ${ }^{3}$ Materials Engineering Department,Faculty of Engineering, University of Kufa, Al- Najaf \\ city, Iraq
}

Email: drsaleh.abbas@uobabylon.edu.iq or salihabbas61@yahoo.com

Email: mat.zoalfokkaralobad@uobabylon.edu.iq

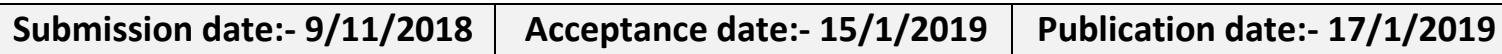

\begin{abstract}
:
The purpose of preparing the review manuscript is to highlight the importance of the physical specifications of the most important of inorganic fillers such as "carbon black" and "silica" that have good physical specifications as surface area, particle size distribution and surface chemistry. Moreover, study the effect of these specifications on the resistance of vulcanized rubber compound for swelling, which is one of the disadvantages to determine the expansion of its uses in industrial applications through the review of many types of research in this area. The results proved that there is a strong relationship between the curing characteristics of the rubber compound such as the time of curing, the scorch time in addition to the "curing rate index' (CRI) and mechanical properties especially the tensile strength and "density of cross-links" for reducing the swelling rate to the minimum. By increasing the "density of cross-links" and improve the specifications of vulcanization and mechanical specifications.
\end{abstract}

Key Words: Inorganic Fillers, Rubber Compound, Swelling rate, Cross-links density, Curing rate index, Particles size, Surface area.

\section{Introduction}

The addition of the fillers to rubber compounds due to increase the mechanical and physical properties vulcanize rubber and reduction the high shrinkage throughout the calendar and the extrusion process. [1]. An important phenomenon in the reinforcement of rubber compounds used in the science of materials witch depends mainly on the "particle size" distribution and the "surface area" of inorganic fillers by interpolating them into the rubber matrix material. Which helps to improve the specifications to meet specific application [2, 3], because the contact area is greater between the inorganic filler and the matrix material, may get better results. The decrease of filler particle size may be a vital for manufacturing the big contact space and reduction the swelling rate [4]. Also, the reduction in particle size results in a lot of industrial application of rubber "nanocomposites" (RNC) and also the dispersion of nanofiller in polymer matrix additional larger than dispersion of standard fillers, like "one-nanosize fillers (layered silicate)", "two-nanosize fillers (carbon nanotube)", "three-nano size fillers" (nanoparticles of metallic oxides or minerals) [5]. On the others hand, the massive "particle size" and low surface activity of fillers because of scale back the reinforcement of composite for instance the silicon dioxide isn't quite reactive to rubber compared with atomic number. Then, the vulcanized time of rubber with silica is longer than with "carbon black" and then the increasing of the overall time lead to decrease the output of Clay. On the other hand, the "nanoclay, talcum, and carbonate" on properties of composites polypropylene and rubber wood fiber', they found the size and form of those fillers had an honest effecting for reduced the water absorption and thickness swelling of the composite specimens, particularly with nanoclay, Srivabut et al ,2018 [6] . 
Natarajan et al, 2018-studied the result of the filler structures on mechanically adjustable elastomer composite, they obtained morphological structures of calcium sulfate, that is acting as an effective filler in flexible elastomer matrix, the quantity of filler reinforcement be reversibly modified that may be reflected in variations of the final stiffness of the material. The higher modulus of the composites, obtained by the unaltered expansion of fine nano-structured calcium sulfate dihydrate crystals, that are created during display to water, in addition of, these strengthening crystals will be changed to a nonreinforcing 'hemihydrate mesocrystalline " structure by only warming the method in a real controlled fashion [7]. Fillers support in vulcanized rubber may be an extremely broad and difficult topic between rubber technologists and researchers [2,8]. The low particle size distribution results in improvement mechanical properties of "bio composites filled", Table 1 shows the technical and empirical values of density of composites crammed by a totally various amount of "cellulosic filler like Wheat bran (WB), wood flour (WF) and micro-cellulose (MC)" [9]. The fillers used because the combining elements in rubber mixtures are three fold. First, they added to the combination to a minimized cost of the outcome. Second, fillers added to the rubber throughout mix to switch the process performance. Fillers considerably have an effect on generality parts of the process performances of rubbers. Presumably, resin combines rubber composites exhibit weak process characters, same according to large throw out swell and great two-mill reduction. Third, sure fillers are supplementary to the mixture for strengthening functions. The times' strengthen has done widely used with rubber technologists to indicate the improvement of force and strength-related characteristics, abrasion resistance, hardness, and modulus [8]. The magnitude of swelling and the final dissolution depends on the solubility parameter of each the materials. Swelling, as hostile dissolution, happens once the quality of the chemical compound molecules restricted by the presence of cross-links, entanglements between molecules and also the association of fillers with the chemical compound. Swelling magnitude relation of a cross-linked polymer system may be a direct line of crosslink density, the smaller magnitude relation of swelling rate was the next degree of crosslink density and improvement of the degree of filler-polymer interaction Boonstra , 1987 [10]. 


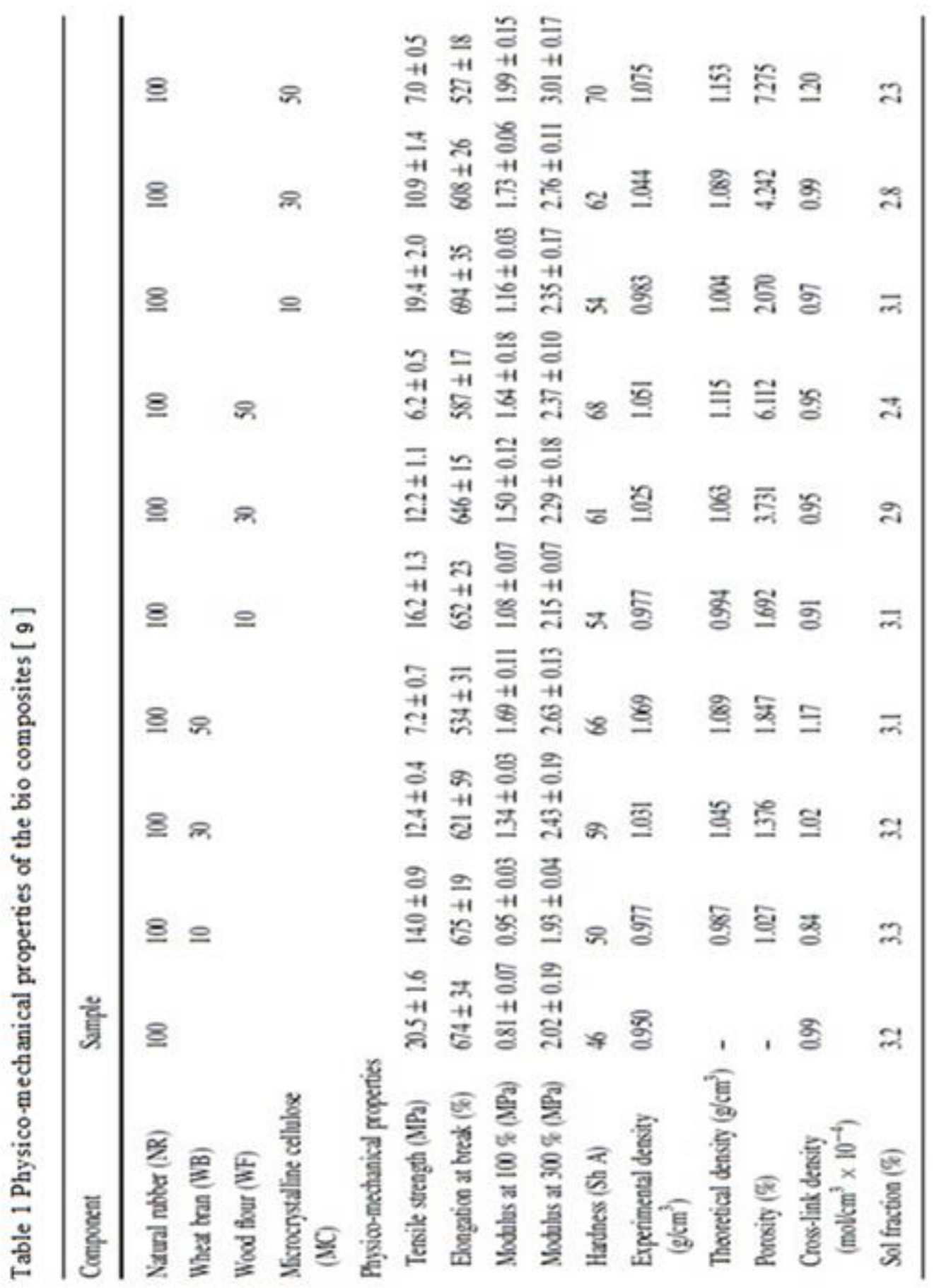

Tong et al, 2018 incorporated the "fumed silica (FSi), precipitated silica (PSi) and modified precipitated silica (MPSi)" for strengthening the silicone rubbers by victimization the "hightemperature vulcanized silicone rubbers (HTV-SRs)". The thermo-oxidative resistance and solvent durability, of the cured silicone rubbers additional, estimated via heat aging take a look at, extraction, and swelling experiments. The mechanical properties "(tensile modulus and tensile strength) at FSi," which can be explained to the molecular interplay between the filler and the matrix. FSi has the best surface area (Table 2), that improves the chemical element bonding interplay within the filler also the silicone matrix. Whereas the changed precipitated, silica was a part of "Si-OH teams" used through the modification. The filler-matrix interaction may additionally make a case for the bottom swelling and sol fraction in "FSi- filled HTV-SR" [11]. The rate of rubber swelling depends on many parameters such as particle size, porosity, and procedure steps, as well as the composition of the polymer network [12]. In turn, the network of fillings depends on the attraction and distance between the agglomerates. Therefore, the use of black carbon pellets spread through the matrix of rubber to all parts of the mix as smaller entities of the aggregates and obtain a large overlap between the particles leads to heterogeneity 
of fillers. Figure 1 shows the structure of the filler agglomerations and their location between the micro-molecules of the polymers. In addition, the carbon blacks have properties that contribute to the formation of large interference with the micro molecules [13]. During this article, a comprehensive review for effecting of the kinds and physical properties of inorganic fillers on physical and mechanical properties of the rubber composite, particularly reduction the swelling rate and proposing some ideas to beat them.

Table 2 Properties of silica fillers [11].

\begin{tabular}{llll}
\hline Properties & FSi & PSi & MPSi \\
\hline $\mathrm{SiO}_{2}(\%$, dry basis) & $\geq 99.9$ & $\geq 98.0$ & - \\
Loss on drying $\left(\%, 2 \mathrm{~h}, 105^{\circ} \mathrm{C}\right)$ & $<1.0$ & 6.8 & 1.79 \\
Ignition loss $\left(400^{\circ} \mathrm{C}\right)$ & $1.0-2.0$ & 2.11 & 5.29 \\
Ignition loss $\left(950^{\circ} \mathrm{C}\right)$ & $1.0-2.0$ & 4.45 & 7.53 \\
DBP absorption value & N.A. & 235 & 172 \\
pH value $(10 \%$ aqueous suspension) & 4.01 & 6.85 & 7.68 \\
BET specific surface area, $\mathrm{m}^{2} / \mathrm{g}$ & 200 & 183 & 148 \\
\hline
\end{tabular}

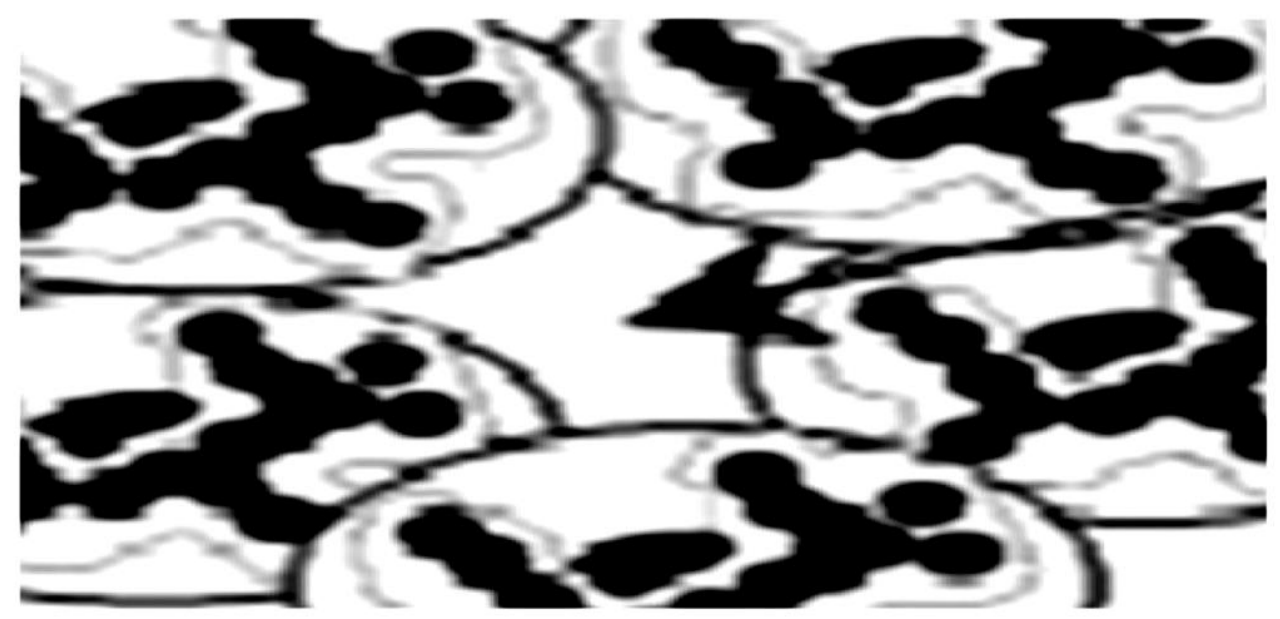

Fig 1. The structure of active filler agglomerates and marked location for trapped rubber macromolecules [13]

\section{The relationship between the cross-links and swelling rate of rubber compound}

Crosslink density values give a thought regarding the matrix-filler interaction [14], for example the cross-linked of "ethylene propylene diene rubbers (EPDM)". Typical filters for stress-strain sensors based on elastomers and reinforced with "carbon nanotubes (CNT)", which have high ratios of elasticity and strength, are evidence of the resistance of the rubber compound to weather, ozone, heat and chemical precipitation. On the other hand, the specifications above for filters come through formation the cross-links between the polymer matrix and carbon nanotubes. Therefore, there is a strong overlap between the individual carbon nanotubes by bonding forces such as Van der Vass bonding, this interaction leads to the formation of a uniform composition on the nanoscale such as "bismaleimide (BM)", "cross-linking of furan-functionalized EPM rubbers". The useful teams on the polymer backbone provide numerous interactions with (defects in the) CNT which will yield sturdiness for succeeding cycles of measurements (Figure 2) [15]. 
Sedov et al, 2018 studied the relation between the swelling rate and 'Cross-linked density of "poly (-caprolactone) (PCL)" which manufactured by using the heated the polymer with various quantities of "radical instigator benzoyl peroxide (BPO)".

The results showed that the enhanced in cross-link density will increase the fraction of the novel instigator (BPO) and decreased the swelling rate (Table 3) [16], which determined by the following equation $[9,11]$.

$. Q=\frac{m_{t-m_{o}}}{m_{o}} x 100 \%$

Wherever "Q is swelling rate, \%; $\mathrm{mt}$ " is mass of the specimen swollen once time $\mathrm{t}, \mathrm{g}$; "mo is an original mass of the specimen, $\mathrm{g}$ ".

The relation between the cross-link density and swelling rate of rubber composite make a case for with the "Flory-Rehner formula" is barely suitable for homogenized rubber specimens with difunctional cross-links, whereas the specimens of rubber composites containing inorganic fillers $[9,15$, $16,17]$.

$V e=\frac{-\left[I n(1-V r)+V r+X V r^{2}\right]}{\left[V 1\left(V r^{\frac{1}{3}}-\frac{V r}{2}\right)\right]}$

Whereve "Ve = cross-link density, mol / cm3; Vr = gel volume within the swollen sample $\leq \mathrm{V} 1$ $=$ solvent molar volume; $\mathrm{X}=$ polymer-solvent interaction parameter

The Flory-Rehner formula be applied for nonfilled compounds, "Kraus correction" for stuffed compounds applied so as to calculate the particular remaining cross-link density in keeping with Eqs (3)،(4) .

$$
\begin{aligned}
& V_{\text {after correction }=} \frac{V e}{1+K x \Phi} \\
& \boldsymbol{\varphi}=\frac{\boldsymbol{\varphi}_{f \times \rho_{r \times m_{o}}}}{\boldsymbol{\rho}_{f \times m_{d r y}}}
\end{aligned}
$$

Where $\mathrm{Ve}$ is the test of the chemical cross-link density $(\mathrm{mol} / \mathrm{cm} 3)$; $\mathrm{V}$ after correction is the real chemical crosslink density $(\mathrm{mol} / \mathrm{cm} 3)$; $\mathrm{K}$ is a fixed property of the filler. However, freelance of the solvent; $\varphi \mathrm{f}$ is that the calculated volume fraction of filler within the specimen; $\rho \mathrm{r}$ is the density of a prepared composite $(\mathrm{g} / \mathrm{cm} 3)$; $\mathrm{m} 0$ is that the weight of specimen before extraction, $\mathrm{g}$; $\rho \mathrm{f}$ is the density of filler $(\mathrm{g} / \mathrm{cm} 3)$; $\mathrm{m}$ dry is that the weight of specimen when extraction $(\mathrm{g})$ [9].

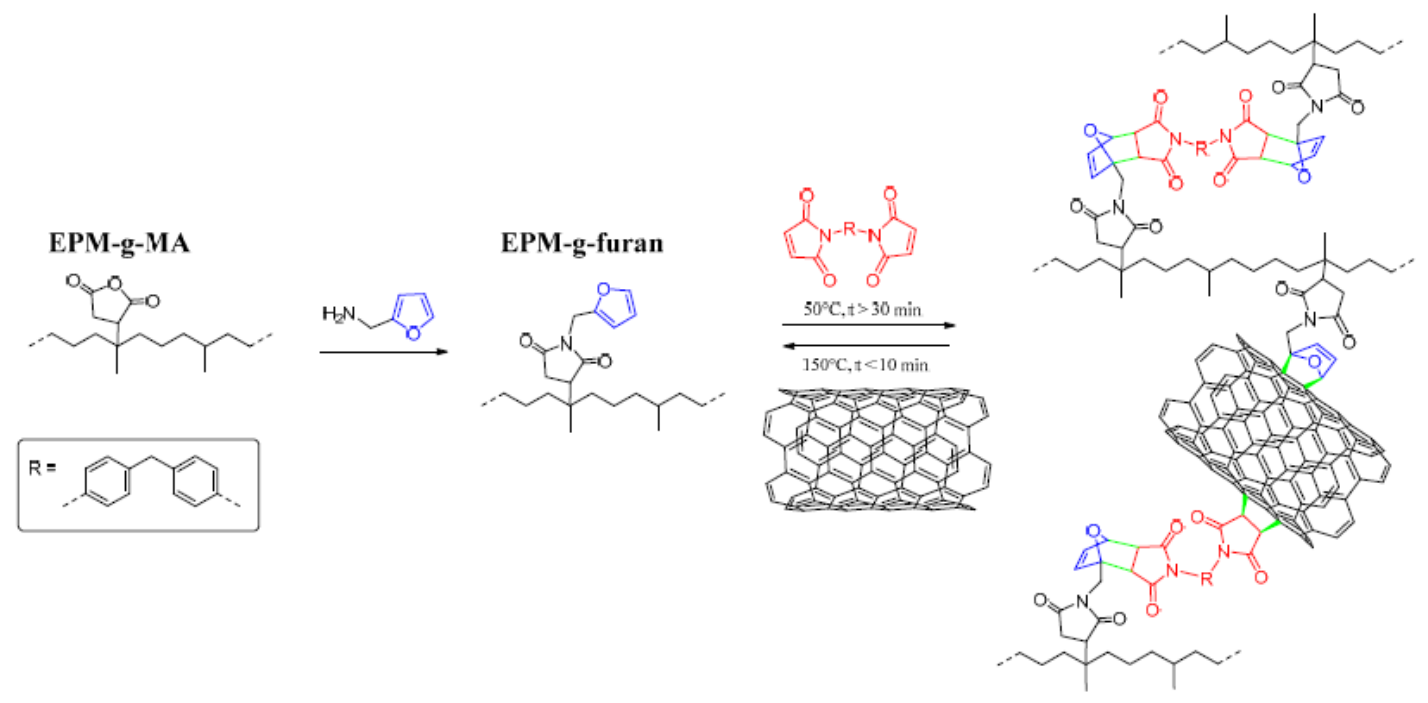

Fig. 2 Furan functionalization and bismaleimide (BM) cross-linking of EPM-g-furan and the integration of CNT fillers via covalent interactions in the thermoreversibly cross-linked network of the nanocomposite [15]. 
Table 3. Swelling ratios cross-link densities, and enthalpies of fusion and crystallization at $10 \mathrm{~K}$. min-1 cooling rate for the samples of PCL and cross-linked PCL obtained using various amounts of BPO [15].

\begin{tabular}{ccccc}
\hline Weight $\%$ of BPO & $Q$ & $\mathrm{~N} / \mathrm{mol} \cdot \mathrm{m}^{-3}$ & $\Delta_{\text {fus }} \mathrm{H} / \mathrm{J} \cdot \mathrm{g}^{-1}$ & $\Delta_{\text {cryst }} \mathrm{H} / \mathrm{J} \cdot \mathrm{g}^{-1}$ \\
\hline 0 & 0 & 0 & $73.5 \pm 2.1$ & $-67.6 \pm 1.9$ \\
1 & & & $72.9 \pm 2.6$ & $-64.3 \pm 2.4$ \\
3 & $14.9 \pm 0.5$ & $48.4 \pm 4$ & $71.7 \pm 1.8$ & $-65.2 \pm 2.1$ \\
5 & $8.2 \pm 0.1$ & $143.3 \pm 4$ & $68.7 \pm 2.4$ & $-65.2 \pm 1.0$ \\
7 & $7.4 \pm 0.2$ & $177.6 \pm 9$ & $67.5 \pm 2.0$ & $-60.6 \pm 1.7$ \\
10 & $6.7 \pm 0.04$ & $209.2 \pm 3$ & $57.3 \pm 1.2$ & $-49.2 \pm 1.8$ \\
\hline
\end{tabular}

3. Effect of physical properties of the inorganic fillers on swelling rate of rubber compound.

\subsection{Effect of particles size and Surface Area of inorganic fillers on swelling rate of rubber compound}

In general, the focus points on nanoscale inorganic fillers materials for strengthening polymeric materials, especially rubber compounds, for wide applications. These fillers used with microns size for having a large surface area and length (length/thickness or length /diameter ratio). Therefore, the elastomers enhanced for raising the modulus of gum rubber [14]. Thus, the reinforcement impact is earned at lower Swelling rate relies on many parameters like "particle size, porosity", drying procedure and structure of polymer network. Particle size plays a vital role in superabsorbent properties; specially, swelling dynamics Composite hydrogels usually show a slower swelling rate as against their clay-free counterparts [12]. Manroshan and Bahrain, 2005 reported the effect of granular particle size of calcium carbonate on physical properties latex films. The results indicate that the time of maturation depends mainly on the rates of loading the filler due to interaction or bonding between the fillers and matrix of the rubber in addition of this result leads to a decrease in the rate of swelling of the rubber [18]. Zaini et al, 2018 investigated the influence of the inorganic filler same "sepiolite (sep) hybridized with Calcium carbonate (CaCO3), silica (Sil) or carbon black (CB)" on hardening method, mechanical properties, thermal stability and flammability of "ethylene propene diene monomer (EPDM)" rubber compounds. Results explained that the small particle sizes of carbon black and silica support higher diffusion of each filler, curatives more refined much as good interaction of CB-sep filler network and (EPDM) chains, also faster starting of crosslinking reaction. In addition, small "particle sizes of CB", giving a large surface area and mixing with the EPDM rubber, and consequently allowing business stress transference (Table 4). Whereas, the increment of "calcium carbonate to the EPDM/sep" composites decreased the tensile strength. This might move from to the larger particle size of carbonate that would not provide an outsized area to act with the rubber matrix, following in ineffective stress shift and below tensile strength. Therefore, the composite same "EPDM/sep/CB composites" displayed an extraordinary enhancement in tensile strength followed by "EPDM/sep/Sil and EPDM/sep/CaCO3 composites. EPDM/ sep /CB" described the excellent thermal stability and enrichment the flammability [19]. Additionally thereto, the smaller particle size of inorganic fillers made a strongest interacting between filler, polymer, and reduction the swelling because of the production of "bonds" in shut nearness to the filler, which both physically and with chemicals combined so, restricted swelling [20].Table 4. Physical properties of sepiolite, silica, calcium carbonate and carbon black [19] 


\begin{tabular}{lllll}
\hline Properties & Sepiolite & Silica & $\begin{array}{l}\text { Calcium } \\
\text { carbon- } \\
\text { ate }\end{array}$ & Carbon black \\
\hline $\begin{array}{l}\text { Density }\left(\mathrm{g} / \mathrm{cm}^{3}\right) \\
\begin{array}{l}\text { Average particle size } \\
(\mu \mathrm{m})\end{array}\end{array}$ & 2.95 & 2.09 & 2.74 & 1.97 \\
$\begin{array}{l}\text { Specific surface area } \\
\left(\mathrm{m}^{2} / \mathrm{g}\right)\end{array}$ & 1.13 & 1.73 & 1.30 & 2.75 \\
\hline
\end{tabular}

\subsection{Effect of the structure of inorganic fillers on swelling rate of rubber composite}

The reinforcement system between carbon black and rubber mainly based on small "particle size that has a large surface area". In addition, there is a physiochemical bond between the filler and the rubber due to the presence of effective aggregates on the filler surface "(such as $-\mathrm{CO},-\mathrm{COOH},-\mathrm{CHO}$, $-\mathrm{OH},=\mathrm{CHOH}) "$. However, the active part, such as area, is not present in carbon fiber, principally as a result of carbon fibers are created through many steps, resulting in destruction of those active teams that are answerable for the great degree of strengthen fixed within the case of strengthening carbon black. The force of rubber-fiber composites depends on the force of the rubber matrix, rubber-fiber intercommunication, the degree of wetting of fiber particles by the rubber organic compound chain. Short carbon fiber may be a non-strengthening filler; hence, the force of the composite is additionally lower. The extent of polymer-filler intercommunication is measurable the passage in swelling rate per the Kraus technique, because of the presence of lower polymer-fiber intercommunication. Just some weak natural interaction mechanical bonding. The low bonding of carbon fiber with rubber matrices managed from SEM photomicrographs of cut surfaces of those composites. (Figure 3) illustrated the loading of 40 "part per hundred rubber (phr)" of the short carbon fiber (F) with rubber mix "NBR/ EPDM For example; NE50.40F represents a 50/50 NBR/EPDM mix including 40 phr" of short carbon fiber. It's obtained that any fibers are separated from the rubber matrix simply, yield the holes of that they became separated during a break. [21]. 


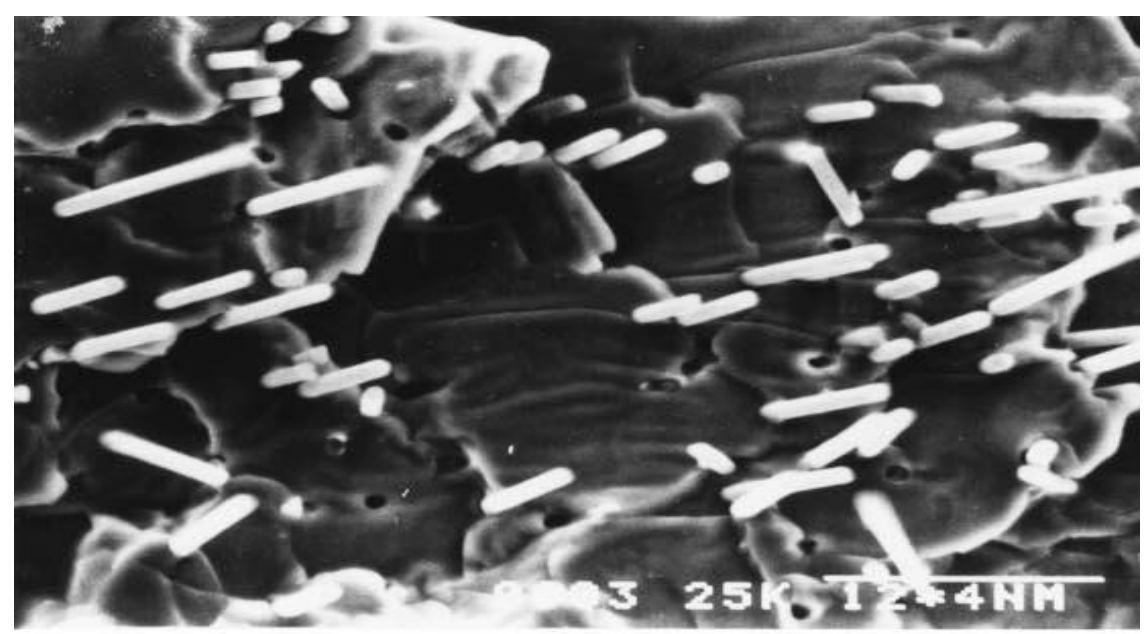

(a)

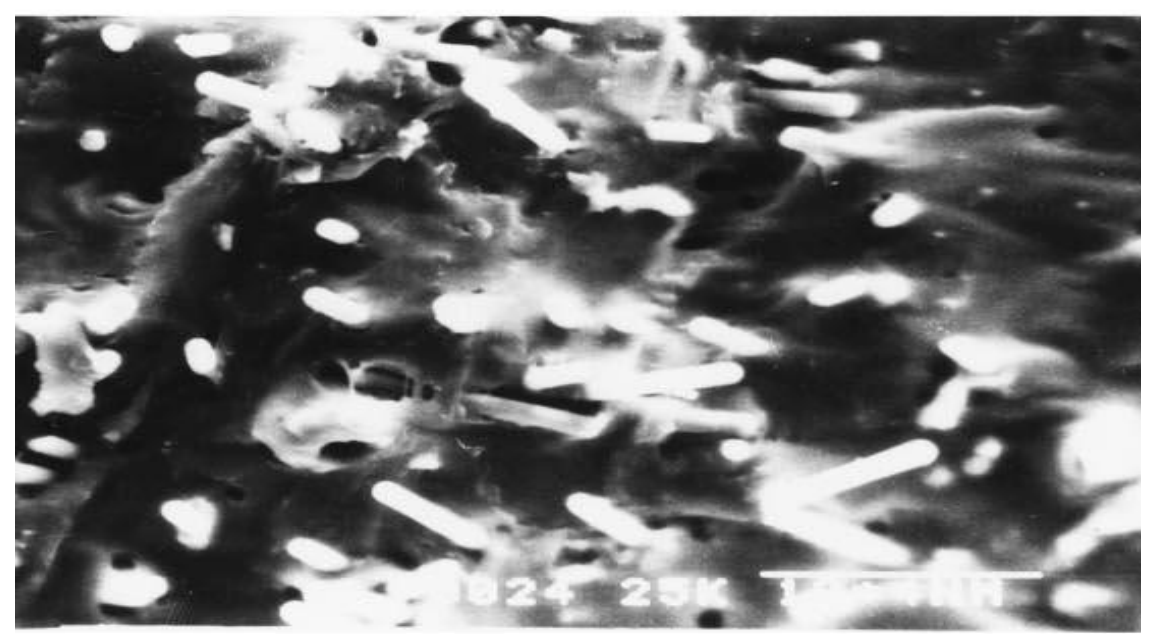

(b)

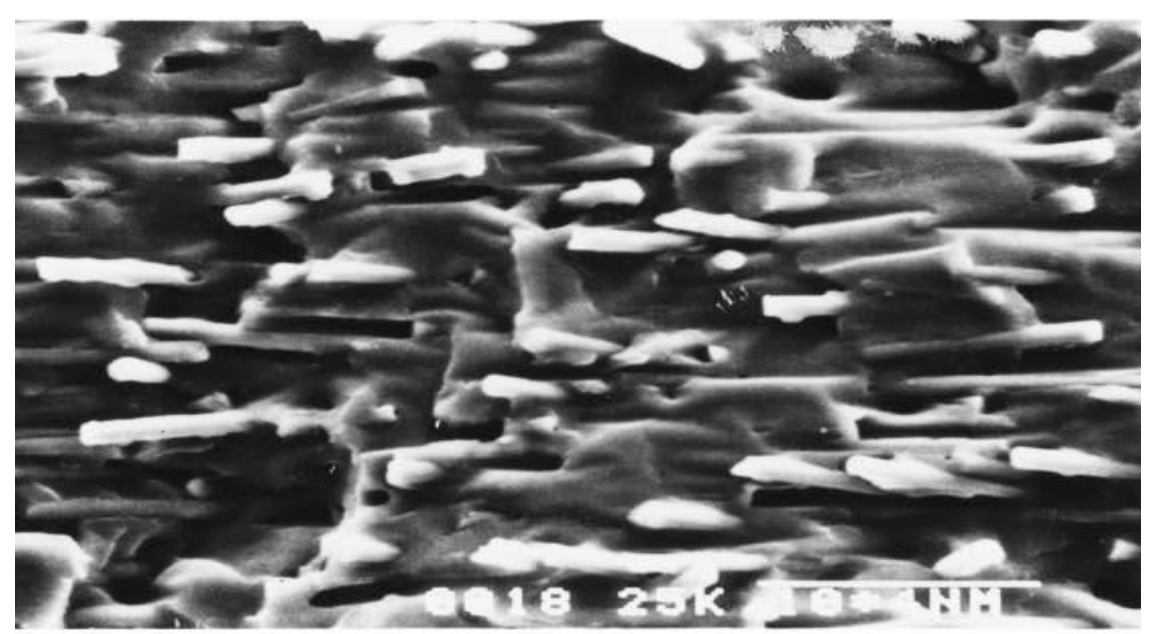

(c)

Fig .3 SEM photomicrographs of brittle fractured surface at $300 \%$ magnification for (a) NE0.40F, (b) NE50.40F, (c) NE100. 40F [21]. 


\section{Conclusion}

The paper discussed several scientific researches that studied the effect of physical properties of inorganic fillers such as particles size and surface area on enhancement of the mechanical properties such as tensile strength and modulus of elasticity, also the density of cross-links, thermal, crystalline and decreasing the swelling rate of rubber compounds. Because, the phenomenon of swelling of vulcanized compounds is a negative phenomenon, which limited the industrial applications of important sector of polymers. Therefore, a lot of scientific research has relied on the accuracy of the selection of inorganic fillers for reinforcement the rubber in terms of selection of good specifications for inorganic fillers, including surface area, distribution of particle size and the structure of the filler. To overcome the problem of swollen vulcanized rubber by increasing the "density of cross-links", improve "mechanical properties" and reduce the "swelling rate" of rubber to the lowest level.

\section{CONFLICT OF INTERESTS.}

- There are no conflicts of interest.

\section{References}

[1] Z.A. Salim, A. Hassan and H. Ismail, "The Effect of High Purity Rice Husk Silica Synthesised using Solvent-thermal Extraction Method on the Properties of Natural Rubber Compounds.", Bio Resources, vol.13,no.3,pp. 6936-51, Jul .2018

[2] M. S. Sobhy,D.E. El-Nashar and N.A. Maziad, "Cure characteristics and physicomechanical properties of calcium carbonate reinforcement rubber composites." Egyptian Journal of solids, vol.27, no.2, pp.241-257, 2003.

[3] Y.Fan,Q. Li, X. Li,D. hee Lee and U.R. Cho, "Comparative study on carboxylated styrene butadiene rubber composites reinforced by hybrid fillers of rice bran carbon and graphite carbon.", Carbon Letters, vol.27,pp.72-80, Jul .2018 .

[4] N.González, M.D.Custal, D. Rodríguez, J.R. Riba and E. Armelin, "Influence of ZnO and TiO2 Particle Sizes in the Mechanical and Dielectric Properties of Vulcanized Rubber." Materials Research, vol.24, no.4, pp. 1082-1091, 2017.

[5] B. Chuong, N.H.Tung, D.V.Hung and N.P.Linh,"Invited review. Natural rubber nanocomposites. "Vietnam Journal of Chemistry, vol.55, no.6, pp.663, Dec .2017

[6] R. Sengupta, S. Chakraborty, S. Bandyopadhyay, S. Dasgupta, R. Mukhopadhyay, K.Auddy and A.S. Deuri, "A short review on rubber/clay nanocomposites with emphasis on mechanical properties." Polymer Engineering \& Science, vol.47, no.11, pp. 1956-1974, Nov.2007.

[7] T.S. Natarajan, S.Okamoto, K.W.Stöckelhuber, S.Wießner,U. Reuter, D. Fischer, A.K.Ghosh, G.Heinrich and A. Das , "In Situ Polymorphic Alteration of Filler Structures for Biomimetic Mechanically Adaptive Elastomer Nanocomposites.", ACS applied materials \& interfaces , vol.10,no.18,pp.16148-1659, Apr.2018.

[8] Z.A. Abdul Salim, A. Hassan and H.A. Ismail, "A Review on Hybrid Fillers in Rubber Composites.", Polymer-Plastics Technology and Engineering, vol.13, no.57, pp.523-539, Apr.2018.

[9] K. Formela, A. Hejna, L.Piszczyk , M.R. Saeb and X. Colom , "Processing and structureproperty relationships of natural rubber/wheat bran biocomposites." Cellulose, vol.23, no.5, pp.3157-3175, Oct.2016.

[10] B. B. Boonstra, "Reinforcement by fillers. The Plastics and Rubber Institute" Rubber Technology and Manufacture, pp. 269-308, 1987.

[11] Y. Tong, H. Liu, A. Chen, H. Guan, J. Kong, S. Liu and C. He, "Effect of surface chemistry and morphology of silica on the thermal and mechanical properties of silicone elastomers." Journal of Applied Polymer Science, vol.135, no.35, pp.46646, Sep.2018.

[12] K. Kabiri, H. Omidian,M.J. Z. ohuriaan-Mehr and S. Doroudiani ,"Superabsorbent hydrogel composites and nanocomposites: a review", Polymer Composites, vol.32,no.2,pp.277-289, Feb .201212 . 
[13] V. Jovanović, J. Budinski-Simendić, J. Milić, A. Aroguz, I. Ristić, S. Prendzov, and L. KorugicKarasz ,"The Effect of Filler Particles on the Properties of Elastomeric Materials Based on Different Network Precursors",In Contemporary Science of Polymeric Materials,L. KorugicKarasz,.; ACS Symposium Series; American Chemical Society: Washington, DC, 2010. DOI: 10. $1021 / \mathrm{bk}-2010-1061$

[14] V.P. Swapna, R. Stephen, T. Greeshma, C. Sharan Dev C and M.S. Sreekala, "Mechanical and swelling behavior of green nanocomposites of natural rubber latex and tubular shaped halloysite nano clay", Polymer Composites, vol.37, no.2, pp.602-611, Feb.2016.

[15] L.M. Polgar, F. Criscitiello, M.van Essen,R. Araya-Hermosilla,N. Migliore, M. Lenti, P. Raffa, F. Picchioni and A. Pucci, "Thermoreversibly cross-linked EPM rubber nanocomposites with carbon nanotubes", Nanomaterials, vol.23, no.8, pp.58, Jan.2018.

[16] I. Sedov, T. Magsumov,A. Abdullin, E. Yarko, T. Mukhametzyanov, A. Klimovitsky and C. Schick , "Influence of the Cross-Link Density on the Rate of Crystallization of Poly ( $\varepsilon$ Caprolactone)", Polymers, vol.10,no.8,pp.902, Aug.2018.

[17] M. Mottaghi, S.N.Khorasani, M.N. Esfahany, A.Farzadfar and M.M.Talakesh , "Comparison of the effect of nano $\mathrm{ZnO}$ and conventional grade $\mathrm{ZnO}$ on the cross-linking densities of NR/BR and NR/SBR blends", Journal of Elastomers \& Plastics, vol.44,no.5,pp.443-451, Sep .2012 .

[18] S. Manroshan and A. Baharin, "Effect of nanosized calcium carbonate on the mechanical properties of latex films", Journal of Applied Polymer Science, vol.96, no.5, pp.1550-1556, Jun.2005.

[19] N.A. Zaini, H. Ismail and A. Rusli , "Sepiolite hybridized commercial fillers, and their effects on curing process, mechanical properties, thermal stability, and flammability of ethylene propylene diene monomer rubber composites", Iranian Polymer Journal, vol.27,no.9,pp.663-675, Sep.2018.

[20] N. Mandal, S.C. Datta, K.M. Manjaiah,B.S. Dwivedi,R. Kumar and P. Aggarwal, "Zincated Nanoclay Polymer Composites (ZNCPCs): Synthesis, Characterization, Biodegradation and Controlled Release Behaviour in Soil", Polymer-Plastics Technology and Engineering, Jan.2018, http://www.tandfonline.com/loi/lpte20

[21] K.P. Sau, T.K. Chaki and D. Khastgir, "Carbon fibre filled conductive composites based on nitrile rubber (NBR), ethylene propylene diene rubber (EPDM) and their blend", Polymer, vol.39.no.25, pp.6461-6471, Dec .1998. 


\title{
ورقة مراجعة حول تأثير الخواص الفيزيائية للحشوات الغير عضوية على معدل انتفاخ المركبات المطاطية
}

\author{
صالح عباس حبيب1 $\quad$ ذو الفقار كريم ال عبيد² \\ 2، 1 قسم البوليمرات والصناعات البتروكيبلاوية، كلية هندسة الدواد، جامعة بابل، مدينة الحلة، العراق \\ 3 قسم هندسة المواد، كلية المندسة، جامعة الكوفة، مدينة النجف، العراق
}

mat.zoalfokkaralobad@uobabylon.edu.iq @ drsaleh.abbas@uobabylon.edu.iq,

\section{الخلاصة:}

ان الغرض من اعداد ورقة المر اجعة هو نسليط الضوء على أهية الخو اص الفيزيائية للحشوات الغير عضوية والمهمة مثل

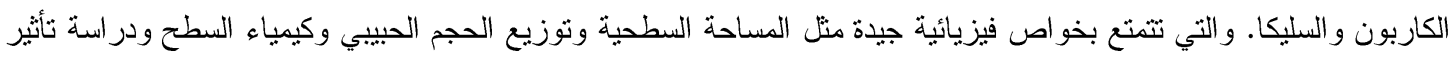

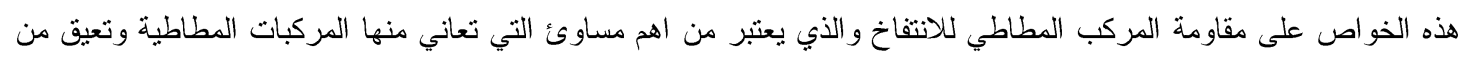

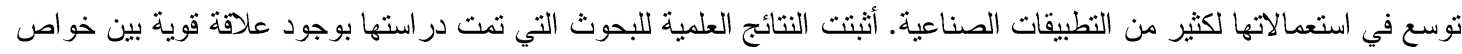

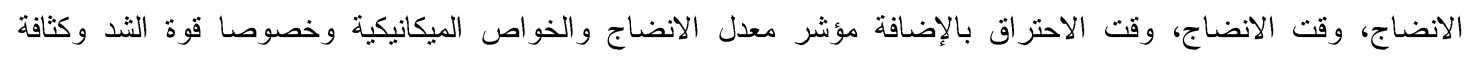

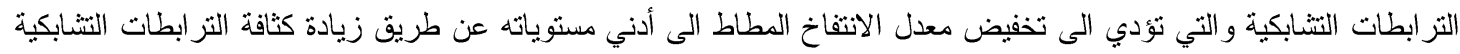
وتحسين خواص الانضاج الخو اص الميكانيكية.

كلمات الداله: الحشوات الغير عضوية، المركب المطاطي، معدل الانتفاخ، كثافة الترابطات التثابكية، مؤشر معل الانضاج، الحجم الحبيبي، المساحة السطحية. 